\title{
Article \\ Development of an Integrated IoT-Based Greenhouse Control Three-Device Robotic System
}

\author{
Vasileios Thomopoulos ${ }^{1}$, Dionysios Bitas ${ }^{2}$, Kyriakos-Nikos Papastavros ${ }^{2}$, Dimitris Tsipianitis ${ }^{2}$ \\ and Angeliki Kavga ${ }^{3, *}$ \\ 1 Department of Computer Engineering \& Informatics, University of Patras, 26504 Patras, Greece; \\ vthomopoulos@upatras.gr \\ 2 Department of Electrical and Computer Engineering, University of Patras, 26504 Patras, Greece; \\ up1031511@upnet.gr (D.B.); up1031523@upnet.gr (K.-N.P.); dtsipianitis@ece.upatras.gr (D.T.) \\ 3 Department of Agricultural Science, University of Patras, 26504 Patras, Greece \\ * Correspondence: akavga@upatras.gr
}

check for updates

Citation: Thomopoulos, V.; Bitas, D.; Papastavros, K.-N.; Tsipianitis, D.; Kavga, A. Development of an Integrated IoT-Based Greenhouse Control Three-Device Robotic System. Agronomy 2021, 11, 405. https://doi.org/10.3390/ agronomy11020405

Academic Editors: Eugenio Cavallo, Roberto Marani and Annalisa Milella

Received: 7 January 2021

Accepted: 17 February 2021

Published: 23 February 2021

Publisher's Note: MDPI stays neutral with regard to jurisdictional claims in published maps and institutional affiliations.

Copyright: (c) 2021 by the authors. Licensee MDPI, Basel, Switzerland. This article is an open access article distributed under the terms and conditions of the Creative Commons Attribution (CC BY) license (https:// creativecommons.org/licenses/by/ $4.0 /)$.

\begin{abstract}
The control of large greenhouse installations, especially those with hydroponics crops, is based on the analysis and use of data recorded by many sensors. At the same time, the size of such installations does not allow for their effective terrestrial surveillance, to detect problems promptly. In recent years, there has been an interest in the development of autonomous agbots equipped with agricultural sensors. Several ground-based AGV (automated guided vehicles) and UAV (unmanned aerial vehicles) systems have been developed for use in open-air plots. A key feature of all these innovative systems is spectroscopy, the development of which has been assisted by the surveillance capabilities and speed of modern-day UAVs (drones). However, there is a lag in the use of spectroscopy inside greenhouses since UAVs do not move freely indoors. In this paper, we propose as a solution a three-device (3DS) system.
\end{abstract}

Keywords: cable-driven parallel robot; cablebot; smart agriculture; precision farming; greenhouses; IoT; interface app; smart irrigation; sensor box

\section{Introduction}

Today, precision agriculture [1] has taken off with the development of autonomous UAVs (Unmanned Aerial Vehicles) also known as drones that help farmers map large areas in a fast and economical way [2,3]. The UAVs provide farmers with data sets, from RGB, spectral, thermal and LiDAR sensors that they carry. Additionally, the data captured by UAVs need to be complemented by other variables such as local climate and soil conditions. A variety of fixed ground stations are cropping up in fields and greenhouses all around the world, collecting soil data and the local climate information. All this information is then fed back to an AI engine to produce an actionable prescription map of fertilizer, irrigation or crop protection needs.

However, a sensor placed at a fixed point in a field or a greenhouse does not necessarily record the critical conditions of temporal and spatial variability necessary to make informed decisions. Furthermore, greenhouse installations lack the benefits of stress maps and prescription maps that can be produced through UAV scouting, as is the case with open fields.

From the thorough focused research, we have conducted and the review of the literature about agriculture cablebots, we may safely presume that agriculture cablebots and agbots is a new scientific area that is now beginning to develop. Accordingly, the existing bibliography is very limited. 


\section{Related Work}

Cablebots to date are mostly experimental devices. The project aim is to introduce precision farming and smart irrigation technologies in a more efficient way, with our integrated Three-Device System (hereinafter referred to as 3DS). The development of this system aims to increase the quantity and quality of agricultural produce, reduce the carbon footprint of the growing process and provide producers with a broad set of usable data, giving them access to the complete picture of their crop at all times.

The proposed 3DS early warning and smart irrigation [4,5] solution for farmers will comprise of a set of technologies that could be applied either as standalone autonomous solutions or as an integrated system of all the above technologies, complete with a manmachine software interface for overall control and final decision making.

The most important microclimate factors for the quality and productivity of plant growth are temperature, humidity, solar radiation and photo-synthetically active radiation (PAR) [6]. Continuous monitoring of these environmental variables provides valuable information to the grower to better understand, how each factor affects growth and how to maximize crop productiveness [7].

\section{System Description}

The proposed solution is a three-device (3DS) system consisting of:

i. A solar-powered cablebot equipped with a spectroscopic camera and an array of other sensors (Figure 1) that will collect data much like a drone in an open-air crop [8,9]. The device is hung from an overhead cable, hence the name cablebot or it can be attached to a slider overhanging from the greenhouse roof.

ii. A flow control valve through which the system will autonomously control the greenhouse irrigation network.

iii. A four-legged ground robot (agbot), a ground-based sensor carrier that can roam the greenhouse and collect data (Figure 2).

Also, we will develop a user interface app code-named 3DS App. This web-based application will act as a portal from which growers will receive processed data from their smart agriculture system on their computer, tablet or mobile device. The robotic system is installed and operates in a pilot production greenhouse at the University of Patras.

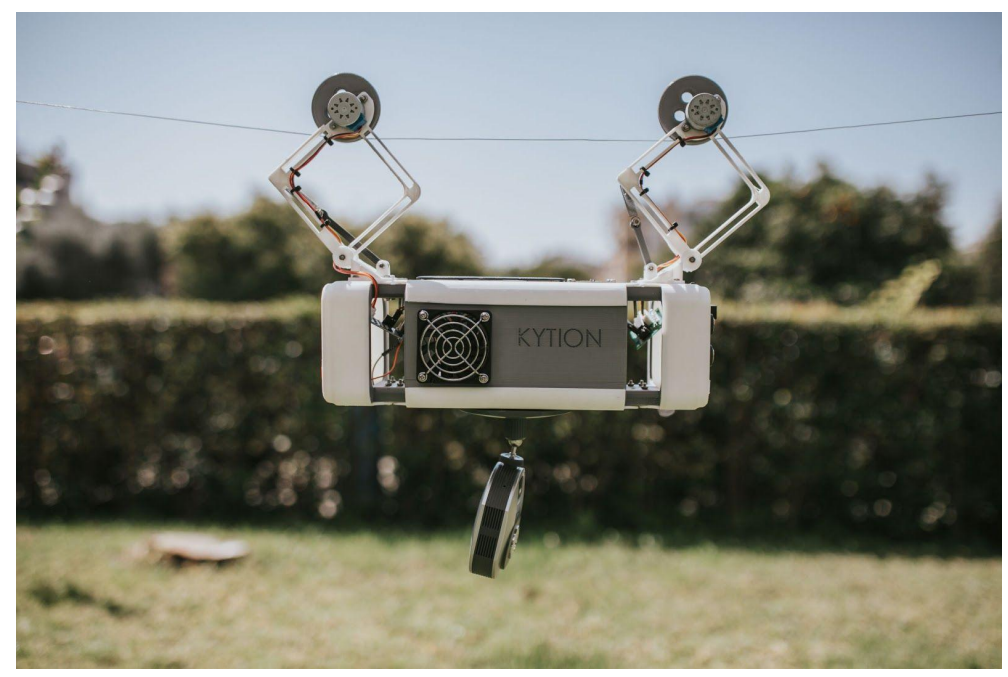

Figure 1. The KYTION cablebot.

The idea is to develop a cost-effective system of autonomous moving platforms equipped with a necessary array of sensors for outdoor and indoor agricultural use. These moving platforms, be it aerial cable bots or ground AGVs, will capture data much like a drone would do inside greenhouses and provide microclimate data and soil sensitive information. With greenhouses and small to medium-sized plots in mind, cable bots present 
an ideal cost/benefit ratio compared to UAVs. To complement the aerial device, a fourlegged agricultural bot (agbot) is also under development that will collect measurements and perform tasks that need to be conducted from the ground, such as soil measurements, weeding, etc. We opted to use a quadruped agbot instead of a wheeled robot, because of the greater better degrees of freedom of movement, the avoidance of obstacles from the skeletal elements of the greenhouse, the arched and not smooth ground irrigation system components, and finally high planting density (Table 1).

This project aims to introduce IoT technologies into greenhouse cultivations [10] turning them in effect into smart installations. It also challenges the authority of drones in precision agriculture scouting, since our devices are also suitable for open-air use, albeit geared towards micro-farm use.

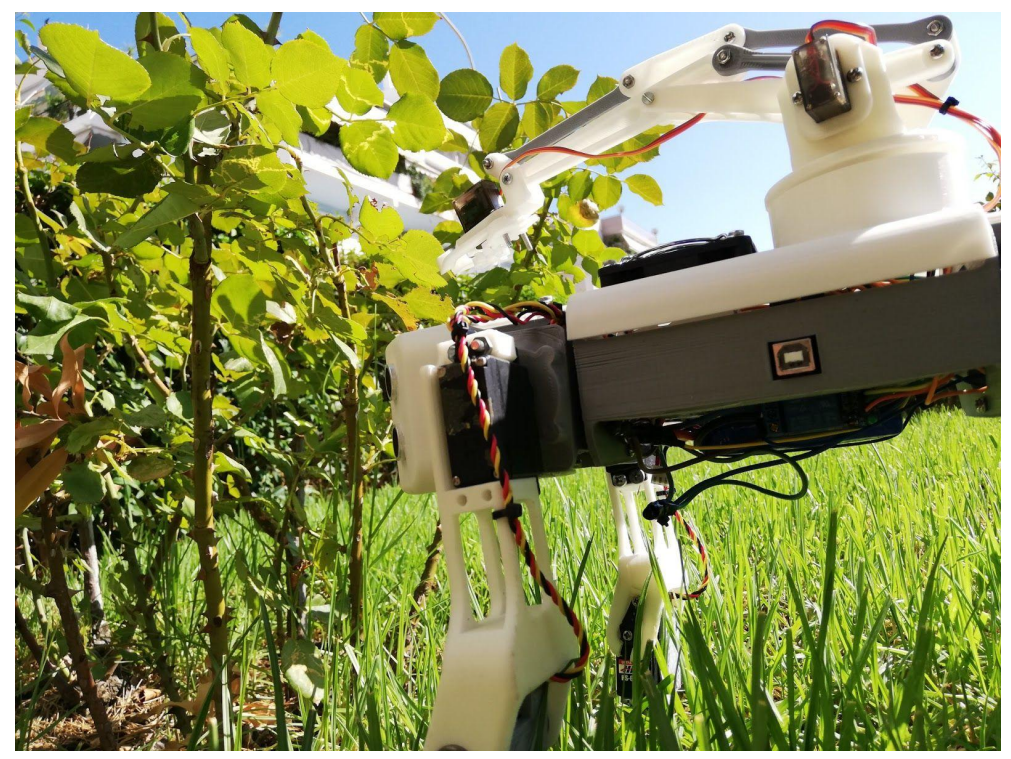

Figure 2. The ground roaming agbot.

Also, our ground roaming agbot is a four-legged dog resembling AGV that can easily overcome obstacles and perform a variety of tasks on uneven ground, as opposed to existing wheeled examples that usually need clear pathways to perform their tasks. It is about time precision agriculture entered greenhouses and became affordable to small plot owners.

Development of a simple solar-powered cablebot (cablebot: a robot that runs suspended from a cable) (Figure 3). A device that will run overhead across greenhouses and small plots, returning data to the plot owner and controlling an electric valve as part of a smart irrigation/fertilization installation. This device will be called Device Aeir (D1). Additionally, a proprietary electric (solenoid) valve will also be designed, with the name Device Flow (D2) that will work in cooperation with the cablebot and will be able to control the smart irrigation piping installation of the given greenhouse or plot. Device Flow will be able to manage 8 irrigation zones upgradeable to 16 . Control zones play a pivotal role in PA (precision agriculture).

According to the stress maps produced by aerial or other means crops are divided into zones for better use of inputs. Areas with different levels of stress need to receive different treatment thus reducing input costs. Development of a quadruped roaming agbot (quadruped: four-legged). Considering that soil sensing is also needed to apply precision agriculture principles with success, the next step is the development of a ground sensor carrier that could roam inside the greenhouse or an open field. The device will be a quadruped suitable for uneven terrain. This device will be called Device Gaia (D3). Finally, a user interface app, code-named 3DS App will be also developed. This web-based application will act as the portal from which growers will receive digested feedback from their smart agriculture system onto their PC, tablet or mobile device [11]. 
The complete approach will integrate data collected from the cablebot Aeir, with data collected from the Gaia agbot and weather data from satellites to produce an autonomous smart irrigation schedule for any plot in question. The benefits of using the 3DS system can be identified at various levels. The farmer receives an overview of his crop and of the potential dangers that may exist or arise. 3DS is expected also to anticipate and to properly handle phenomena that could damage a crop. The physical presence of the grower in the field is greatly reduced as 3DS automates irrigation and sends real-time information to the grower. The smart irrigation system contributes positively to irrigation water savings [12]. Water doses for the cultivated species in the greenhouse conditions will be determined in the beginning by the plants surroundings area and plants parameters, and will be improved and adapted by the analysis of data collected from the 3DS system.

Table 1. KYTION Aeir comparison with drones and fixed sensors.

\begin{tabular}{cccc}
\hline & KYTION Aeir & Drone & Fixed Sensor \\
\hline Soil sensing & $x$ & $x$ & $\checkmark$ \\
Sunlight sensing & $\checkmark$ & $x$ & $x$ \\
Rain sensing & $\checkmark$ & $x$ & $\checkmark$ \\
Humidity sensing & $\checkmark$ & $x$ & $\checkmark$ \\
Temperature sensing & $\checkmark$ & $\checkmark$ & $\checkmark$ \\
RGB camera/sensor & $\checkmark$ & $\checkmark$ & $x$ \\
Spectral camera/sensor & $\checkmark$ & Needs operator & User defined \\
Measurement frequency & User defined & $\checkmark$ & $x$ \\
Spraying/Weeding & $x$ & $\checkmark$ & $x$ \\
Fertilizer application & Flow valve & $x$ & $x$ \\
Irrigation & Flow valve & large & small \\
Max area coverage & 4 hectares & &
\end{tabular}

The core of competitiveness lies in 3DS ability to integrate data from a variety of sources into a single straight forward application that will assist farmers with their dayto-day operations [13]. The area of ground robots still has substantial ground to cover for those technologies to break into the commercial market. To this respect, the research team has already conducted an extensive market analysis on a global scale, and we have identified all the key players in PA that provide hardware and software solutions.

Worldwide concern about food security and environmental conservation is evident presently. Recent technological advancements in IoT, GPS guided aerial and ground vehicles, molecular biology and AI neural networks have spurred a global investment trend towards ag-tech and food-tech, to remedy for those threats that may lie ahead [14]. The overall aim is to introduce cost-effective spectral imaging inside greenhouses [15]. 3DS reduces the initial cost of PA deployment for farmers.

D1 will be the first device to be developed since we will need to also adjust its physical deployment inside the test greenhouse. As soon as D1 becomes operational, D2 will be developed and all the communication protocols between the two devices will be tested. As soon as we establish the connection, work will commence on the control app so that we start to receive some digested information and begin to design its front end. Finally, work will commence on D3. As D3 will be using the same communication protocols (already developed) our effort will be in developing its kinematics and machine vision so that it moves freely inside confined areas (Table 2). 

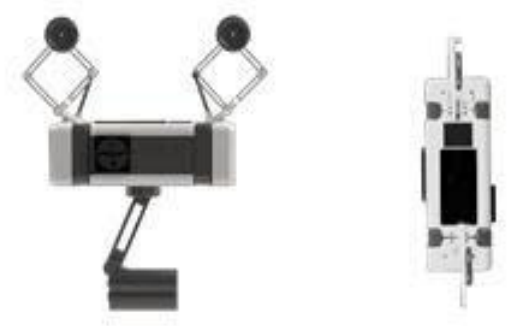

Figure 3. The cablebot.

Table 2. Device functionalities.

\begin{tabular}{ll}
\hline Device & Functionalities \\
\hline Device 1 (D1), Cablebot & (i) Development of functional 3D design software for D1 Cablebot printing \\
& (ii) Design of its functional circuits with all the necessary hardware \\
& (iii) Software programming of all the individual components of the system (Xbee \\
for communication, Raspberry and/or Arduino for control) \\
(iv) Overall check of the proper operation of the device and its components
\end{tabular}

Device 3 (D3), Quadruped Agbot (i) Development of a functional 3D design software for the quadruped printing

(ii) Design of its functional circuits with all the necessary hardware

(iii) Programming of all the individual components that make up the system and solving kinematics algorithms for its precise motion

(iv) Overall check of the proper operation of the system and its communication protocols with D1 and D2

Support/Control App

(i) Development of a prototype user interface app that feeds the end-user with digested information and data from the coordinator.

(ii) Check and double-check for user-friendliness (easy to follow and understand)

(iii) Improved graphical design

(iv) Add-on functions such as manual override etc.

\section{Operational Methodology}

The cablebot (D1) will collect data and send it to the coordinator/flow valve (D2) system. D2 will process the collected data and instruct accordingly the solenoid valve attached to the zonal irrigation system of a given greenhouse installation or plot. Data will also be automatically uploaded to our server as backup. The agbot (D3) will act as a support device that inspects up-close any stress areas identified by D1 and will conduct soil sensing at random points in the plot/greenhouse (Figure 4). Various other capabilities are to be addressed at a second stage (possibly another research project) (Table 3). 
Table 3. Technical Characteristics of the 3DS System.

\begin{tabular}{|c|c|c|c|}
\hline & $\begin{array}{l}\text { KYTION Aeir } \\
\text { (Cablebot) }\end{array}$ & $\begin{array}{l}\text { KYTION Gaia } \\
\text { (Agbot) }\end{array}$ & $\begin{array}{c}\text { KYTION Flow } \\
\text { (Flow Control Valve) }\end{array}$ \\
\hline Soil sensing & $\mathrm{n} / \mathrm{a}$ & $\checkmark$ & $\checkmark$ \\
\hline Sunlight sensing & $\checkmark$ & $\checkmark$ & $\mathrm{n} / \mathrm{a}$ \\
\hline Rain sensing & $\checkmark$ & $\checkmark$ & $\mathrm{n} / \mathrm{a}$ \\
\hline Humidity sensing & $\checkmark$ & $\checkmark$ & $\mathrm{n} / \mathrm{a}$ \\
\hline Temperature sensing & $\checkmark$ & $\checkmark$ & $\mathrm{n} / \mathrm{a}$ \\
\hline RGB images & $\checkmark$ & $\checkmark$ & $\mathrm{n} / \mathrm{a}$ \\
\hline Spectral sensing/images & $\checkmark$ & $x$ & $\mathrm{n} / \mathrm{a}$ \\
\hline Measurement frequency & Every hour & User defined & $\mathrm{n} / \mathrm{a}$ \\
\hline Spraying & $x$ & to be determined & $x$ \\
\hline Fertilizer application & $x$ & $x$ & $\checkmark$ \\
\hline Irrigation & $\mathrm{n} / \mathrm{a}$ & $\mathrm{n} / \mathrm{a}$ & $\checkmark$ \\
\hline Autonomy & Solar-powered & 1 hour & Solar-powered \\
\hline Guidance & cable & GPS & $\mathrm{n} / \mathrm{a}$ \\
\hline Obstacle recognition & $x$ & $\checkmark$ & $\mathrm{n} / \mathrm{a}$ \\
\hline Ingress protection & IP67 & IP67 & IP67 \\
\hline Battery & LiPo 2400 mAh & to be determined & \\
\hline communication protocol & Xbee & Xbee & Xbee \\
\hline Max area coverage & 4 hectares & 10 hectares & 10 hectares \\
\hline Management Zones & $\mathrm{n} / \mathrm{a}$ & $\mathrm{n} / \mathrm{a}$ & 8 or 16 \\
\hline
\end{tabular}

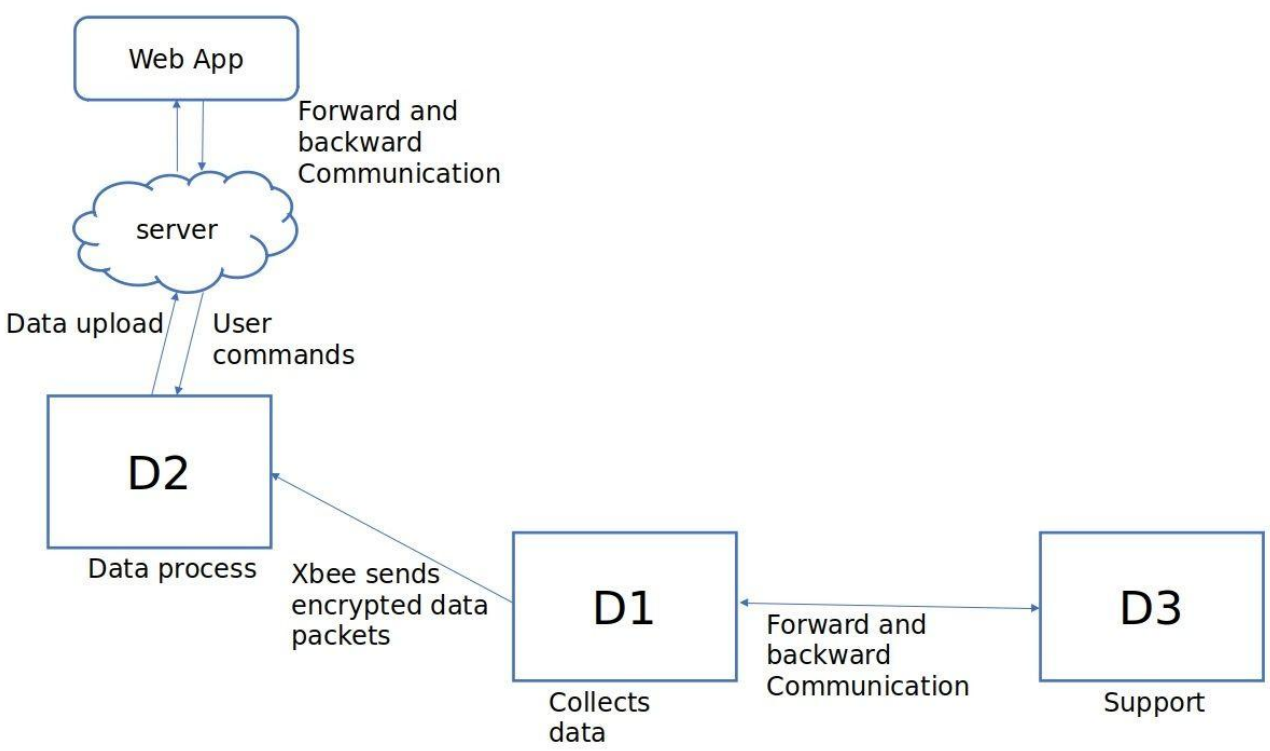

Figure 4. Operational Method of the 3DS System.

D1 Operation: The operation of D1 is to be controlled by an Arduino Pro Mini which controls the time intervals between data collection and the overall device movement. The whole process will be controlled by an automatic relay to avoid unnecessary waste of energy. A 12-volt operation is to be achieved through a buck converter (Figure 5). 


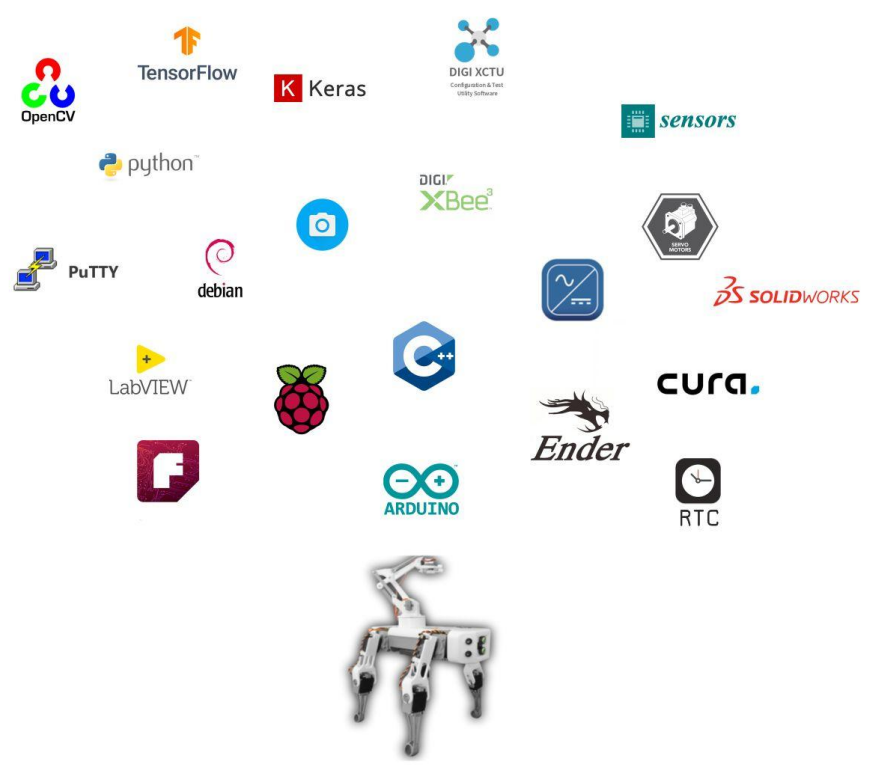

Figure 5. Technologies used in our system.

\subsection{Cablebot}

The movement of the cablebot along the cable is achieved through brushless motors and its speed is $3.5 \mathrm{~m} / \mathrm{s}$. The operation of the system is controlled by an Arduino Pro Mini that controls the time intervals between data collection and device movement. The process is controlled by an automatic relay to avoid unnecessary waste of energy. Operation is achieved with a voltage of 12 volts through a buck converter. Data from the built-in sensors is collected via a built-in Arduino NANO. Once the Arduino NANO has successfully taken measurements (via the tx-rx pins), it sends a signal to the Arduino Pro Mini so that the latter puts the device in standby mode.

Communication between D1 and D2 then begins via Xbee technology, which sends encrypted data packets to the tuning/streaming unit. Once the data is successfully transmitted, it is decoded by a node-mcu. The data is then uploaded to our database. The offered vehicle weighs $930 \mathrm{~g}$ and can operate properly in temperatures from $-5{ }^{\circ} \mathrm{C}$ to $45^{\circ} \mathrm{C}$, for critical elements (batteries, motors, navigation sensors, etc.) includes backup systems to ensure smooth operation even in cases of individual failure (mainly) subsystems. The basic operation control is done by a computer system with a variety of redundancy components. The vehicle will be delivered with a Li-on technology battery with a capacity of $3000 \mathrm{mAh}$ and operating voltage $2 \mathrm{~S}(7.4 \mathrm{~V})$, where in combination with the solar panel it can operate autonomously for at least a month. It should be noted that Li-on battery technology is more durable in solar systems than competing battery technologies such as Lipo (Figure 6).

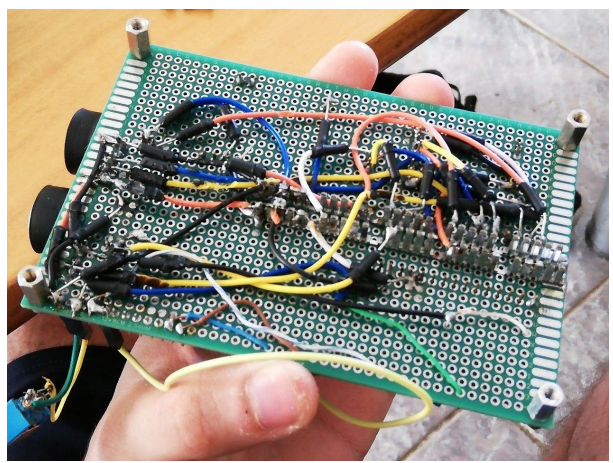

Figure 6. Communication between D1 and D2. 


\subsection{Coordinator}

KYTION flow (the flow coordinator/valve). Once the data is successfully transmitted, it is decoded by a node-mcu chip. The data is then uploaded to our database. Node-mcu and not ESP has been selected so that the voltage can be easily converted via the Vin pin. The moderator also has an LCD screen for debugging. Irrigation/fertilization decisions are made through thresholds as all data collected is analyzed and combined with data from external sources, such as satellite weather data, etc. All data processing is done locally so that it does not depend on 3G/4G network availability on site. Using this set of weather parameters, namely temperature $(\mathrm{T})$, relative humidity $(\mathrm{RH})$, wind speed $(\mathrm{U})$ and average daily radiation (Rn), the Penman-Monteith equation produces an ETo reference evapotranspiration rate, which can be used to compares water loss from day to day so that it can calculate the amount of water for irrigation. If a potential hazard or critical situation is detected, the end-user receives a notification through the application. The control/user interface tool has been developed using the Node-Red tool. The back end serves as a programming interface and the front end serves as a user interface.

\subsection{Sensors}

The offered system includes a relative humidity sensor (Relative humidity sensor) with a measuring range of $20 \%$ to $95 \%$. The offered vehicle has an RGB camera with $5 \mathrm{mp}$ and $720 \mathrm{p}$ video recording as well as $2 \mathrm{x}$ optical zoom for troubleshooting in remote cultivation, this function is compatible with any mobile device or PC with an internet connection. The multispectral RGB camera records the spectral image of plants and assesses their water and nutritional status, as well as potential hazard from pests and diseases. It also has a temperature sensor from $0{ }^{\circ} \mathrm{C}$ to $50^{\circ} \mathrm{C}$, air synthesis sensor $\left(\mathrm{CO}_{2} \mathrm{VOCs}\right)$, UVA sunshine sensor $(365 \pm 10 \mathrm{~nm}), \mathrm{UVB}(330 \pm 10 \mathrm{~nm})$ and ground humidity sensor $0 \%$ to $70 \%$. Finally, the offered system will have suitable sockets for all the sensors, which have been described. These sockets can be easily removed or added by the operator so that the desired sensors can be used at any time.

\subsection{Web Application}

The web application of the system displays clearly and in an easy-to-understand way all the measurements that the system receives. Since the app is web-based it is iOS and Android compatible automatically. The user can access real-time measurements and system settings, it is also possible to remotely collaborate and share files with members of a group that the user will select. All data collected by the system can be exported to any farm management software. The application is in cloud format with minimal requirements on hardware equipment for data processing.

\section{Data Collection and Transmission}

Data shall be collected on vegetables and flowers in a greenhouse installation of the Agriculture Department of University of Patras. The installation is a fully equipment modified arched greenhouse made of high-quality materials. It is the result of scientific design and advanced technology. The frame consists of steel construction elements of different cross-sections according to European specifications. The greenhouse roof is covered with sheets of hard polycarbonate plastic. These sheets are resistant to chemicals, acids, detergents but also salt, sea air and pollution. They are not flammable. They can absorb impact with hail with a diameter of $20 \mathrm{~mm}$ and an $80 \mathrm{~km} / \mathrm{h}$ speed.

The greenhouse is equipped with the following technologies:

- Meteorological station with embedded specialized instruments and sensors for monitoring and controlling greenhouse micro and macroclimate. Indicatively reported: Datalogger (CR1000X) with two relay analog multiplexer units

- Sensors, including a silicon type pyranometer (model SPLITE), a Thermopile-type pyranometer (model CMP3), a Photo-synthetically active radiometer (model PARLITE), a Pyrgeometer (model CGR3), a temperature and relative humidity probe 
(model MP101A), a Temperature and relative humidity probe (model S3CO3), a rain gauge (model 52203), an anemometer (model A100K) with threshold sensitivity $0.15 \mathrm{~m} \mathrm{~s}^{-1}$

- Analyzer Datalogger Software

- Photovoltaic panel and accumulators of electricity

Data from the D1 embedded sensors is to be collected through an integrated Arduino NANO. The D1 embedded sensors are:

- $\quad$ Temperature sensor ( $\mathrm{Ta} \_$glass in ${ }^{\circ} \mathrm{C}$ )

- Relative humidity sensor (RH_glass in \%)

- Radiation sensor (Sol_glass in Watt $/ \mathrm{m}^{2}$ )

- PAR sensor (Par_glass $\mu \mathrm{mol} \cdot \mathrm{s}^{-1} \cdot \mathrm{m}^{-2}$ )

- Multispectral camera [16]

In the future, other sensors e.g., $\mathrm{CO}_{2}$ concentration, air composition and quality et cetera could be installed.

A pilot greenhouse installed at the University of Patras is used, as the main test bed of the proposed technologies. The East-West axis of the greenhouse is designed in such a way that it has an absolute physical resemblance to productive greenhouses. Its dimensions are as follows: width: $9.60 \mathrm{~m}$, length: $12.0 \mathrm{~m}$, gutter height: $4.00 \mathrm{~m}$, ridge height: $6.50 \mathrm{~m}$, area of the greenhouse: $115.2 \mathrm{~m}^{2}$.

During the D1 oval movement inside of the greenhouse, all data were continuously recorded at the South and North sides, providing averages every $10 \mathrm{~min}$. Data were stored in a data logger (CR1000X, Measurement and control module, Campell Scientific, Logan, UT, USA) with a relay analog multiplexer. Overall daytime and night-time mean values were also computed from the respective time series, based on the interval between the steep radiation and temperature changes at sunrise and sunset. The two following tables demonstrate the data collected from the pilot D1 installation in the pilot greenhouse (Tables 4 and 5). 
Table 4. Mean day-time variations of climatic parameters over the measurement period.

\begin{tabular}{|c|c|c|c|c|c|c|c|c|}
\hline Date/Time & Ta_Glass_S & RH_Glass_S & Ta_Glass_N & RH_Glass_N & Sol_Glass_S & Par_Glass_S & Sol_Glass_N & Par_Glass_N \\
\hline 5 March 2020 & 34.08 & 49.3 & 32.30 & 51.27 & 284.94 & 530.54 & 230.99 & 446.76 \\
\hline 6 March 2020 & 26 & 63.34 & 24.98 & 58.91 & 208.17 & 395.84 & 171.18 & 319.48 \\
\hline 7 March 2020 & 28.15 & 70.69 & 26.45 & 68.26 & 207.27 & 391.22 & 173.17 & 326.04 \\
\hline 9 March 2020 & 20.89 & 69.65 & 20.38 & 68.54 & 129.25 & 238.71 & 131.87 & 228.97 \\
\hline 10 March 2020 & 22.6 & 82.85 & 22.48 & 86.56 & 144.66 & 272.47 & 125.91 & 245.64 \\
\hline 11 March 2020 & 19.21 & 92.51 & 19.02 & 93.59 & 91.92 & 153.44 & 96.3 & 154.79 \\
\hline 12 March 2020 & 31.16 & 48.86 & 29.81 & 52.35 & 335.82 & 629.85 & 247.24 & 468.26 \\
\hline 14 March 2020 & 29.66 & 37.01 & 28.37 & 38.95 & 328 & 613.46 & 243.23 & 460.84 \\
\hline 15 March 2020 & 28.18 & 41.14 & 27.47 & 40.38 & 277.35 & 520.93 & 215.79 & 391.58 \\
\hline 16 March 2020 & 28.7 & 44.46 & 28.2 & 42.35 & 279.45 & 514.62 & 210.4 & 418.34 \\
\hline 17 March 2020 & 30 & 39.16 & 28.9 & 39.68 & 345.32 & 635.6 & 278.56 & 529.15 \\
\hline 18 March 2020 & 28.19 & 51.02 & 27.02 & 48.19 & 326.32 & 604.69 & 268.5 & 492.75 \\
\hline 19 March 2020 & 28.78 & 57.32 & 26.84 & 55.91 & 299.2 & 566.95 & 252.03 & 475.54 \\
\hline 20 March 2020 & 31.97 & 51.76 & 30.17 & 49.26 & 337.58 & 630.09 & 270.83 & 527.22 \\
\hline 21 March 2020 & 29.19 & 58.88 & 27.84 & 55.32 & 288.39 & 541.08 & 252.26 & 489.47 \\
\hline 22 March 2020 & 28.81 & 60.22 & 26.94 & 60.97 & 275.01 & 522.12 & 212.22 & 436.47 \\
\hline 24 March 2020 & 37.27 & 64.98 & 35.42 & 68.83 & 367.51 & 682.22 & 289.22 & 550.03 \\
\hline 25 March 2020 & 30.18 & 54.77 & 29.12 & 52.5 & 363.36 & 686.81 & 283.95 & 549.46 \\
\hline 26 March 2020 & 27.67 & 72.48 & 26.15 & 73.55 & 256.14 & 480.68 & 216.86 & 422.63 \\
\hline 27 March 2020 & 27.63 & 52.84 & 28.05 & 52.2 & 325.96 & 621.44 & 266.63 & 519.54 \\
\hline 28 March 2020 & 28.99 & 44.89 & 27.51 & 43.98 & 342.19 & 659.81 & 278.95 & 536.74 \\
\hline 29 March 2020 & 25.9 & 43.3 & 24.94 & 40.42 & 323.83 & 634.71 & 274.22 & 536.77 \\
\hline 30 March 2020 & 22.88 & 52.26 & 23.89 & 49.49 & 223.7 & 429.19 & 182.75 & 349.46 \\
\hline 31 March 2020 & 32.09 & 33.30 & 31.83 & 31.6 & 353.34 & 668.74 & 265.65 & 531.74 \\
\hline 1 April 2020 & 31.76 & 39.59 & 32.08 & 36.1 & 373.87 & 696.76 & 273.87 & 519.57 \\
\hline 2 April 2020 & 27.59 & 56.45 & 27.85 & 51.86 & 310.05 & 576.84 & 249.91 & 485.72 \\
\hline 3 April 2020 & 21.52 & 80.71 & 21.1 & 79.47 & 95.36 & 138.9 & 79.5 & 130.88 \\
\hline 4 April 2020 & 30.44 & 49.79 & 29.74 & 48.53 & 387.86 & 743.83 & 274.85 & 548.14 \\
\hline 5 April 2020 & 25.87 & 61.52 & 25.31 & 60.43 & 254.55 & 474.1 & 185.62 & 365.99 \\
\hline 6 April 2020 & 27.45 & 59.39 & 27.16 & 59.7 & 277.65 & 511.92 & 205.4 & 409.82 \\
\hline 7 April 2020 & 28.42 & 59.79 & 28.36 & 57.5 & 306.97 & 574.02 & 230.17 & 432.73 \\
\hline
\end{tabular}


Table 4. Cont.

\begin{tabular}{|c|c|c|c|c|c|c|c|c|}
\hline Date/Time & Ta_Glass_S & RH_Glass_S & Ta_Glass_N & RH_Glass_N & Sol_Glass_S & Par_Glass_S & Sol_Glass_N & Par_Glass_N \\
\hline 8 April 2020 & 29.53 & 46.62 & 29.23 & 44.84 & 403.57 & 757.42 & 281.44 & 541.9 \\
\hline 9 April 2020 & 30.99 & 42.96 & 30.11 & 38.80 & 380.19 & 706.58 & 287.66 & 555.56 \\
\hline 10 April 2020 & 29.56 & 46.96 & 28.72 & 41.59 & 319.07 & 596.21 & 260.68 & 493.43 \\
\hline 12 April 2020 & 31.53 & 51.66 & 30.06 & 49.91 & 395.53 & 734.23 & 275.42 & 539.44 \\
\hline 13 April 2020 & 31.63 & 48.83 & 30.4 & 47.24 & 395.95 & 734.44 & 278.25 & 543.06 \\
\hline 14 April 2020 & 31.74 & 51.6 & 29.99 & 50.43 & 396.89 & 749.66 & 280.10 & 548.55 \\
\hline 15 April 2020 & 30.64 & 55.81 & 29.13 & 54.11 & 390.45 & 750.83 & 278.33 & 549.57 \\
\hline 17 April 2020 & 25.98 & 78.45 & 24.63 & 78.99 & 249.56 & 469.63 & 192.74 & 375.78 \\
\hline 18 April 2020 & 28.28 & 59.6 & 26.4 & 60.55 & 380.6 & 725.82 & 293.97 & 594.08 \\
\hline 19 April 2020 & 23.77 & 63.3 & 22.34 & 64.36 & 322.17 & 615.24 & 261.14 & 494.47 \\
\hline 20 April 2020 & 23.45 & 48.66 & 22.45 & 48.31 & 329.52 & 629.69 & 276.42 & 528.42 \\
\hline 21 April 2020 & 23.89 & 56.11 & 22.52 & 55.31 & 342.04 & 641.4 & 264.46 & 496.45 \\
\hline 22 April 2020 & 21.75 & 65.32 & 20.33 & 65.37 & 258.96 & 460.58 & 203.52 & 358.35 \\
\hline 23 April 2020 & 27.47 & 56.69 & 25.03 & 59.71 & 381.52 & 707.02 & 282.82 & 526.26 \\
\hline 24 April 2020 & 25.45 & 52.13 & 23.26 & 52.91 & 408.54 & 791.58 & 299.65 & 567.63 \\
\hline 25 April 2020 & 27.86 & 62.05 & 25.65 & 66.11 & 398.53 & 759.72 & 288.75 & 554.5 \\
\hline 27 April 2020 & 29.42 & 51.87 & 26.53 & 52.54 & 400.02 & 759.33 & 310.48 & 594.01 \\
\hline 28 April 2020 & 28.66 & 47.14 & 26.15 & 49.32 & 388.17 & 733.43 & 300.15 & 563.17 \\
\hline 29 April 2020 & 26.38 & 45.96 & 23.95 & 47.37 & 272.38 & 504.41 & 227.09 & 428.95 \\
\hline 30 April 2020 & 28.34 & 61.2 & 26.12 & 66.21 & 340.09 & 650.87 & 269.33 & 510.95 \\
\hline 1 May 2020 & 29.64 & 64.3 & 27.61 & 67.29 & 373.34 & 710.38 & 289.33 & 550.5 \\
\hline 2 May 2020 & 29.92 & 64.48 & 27.68 & 69.35 & 366.97 & 698.91 & 282.51 & 534.17 \\
\hline 3 May 2020 & 28.5 & 59.71 & 25.98 & 63.27 & 375.5 & 731.28 & 286.65 & 506.65 \\
\hline 4 May 2020 & 28.43 & 57.11 & 25.82 & 59.18 & 355.33 & 680.46 & 269.17 & 520.95 \\
\hline 5 May 2020 & 27.17 & 58.59 & 24.48 & 61.74 & 356.05 & 710.45 & 296.98 & 579.83 \\
\hline 6 May 2020 & 28.28 & 56.19 & 25.81 & 60.49 & 330.97 & 659.75 & 281.51 & 551.08 \\
\hline 7 May 2020 & 25.57 & 56.27 & 23.64 & 56.93 & 322.2 & 627.54 & 276.78 & 531.5 \\
\hline 8 May 2020 & 27.07 & 57.35 & 24.63 & 59.09 & 363.79 & 707.84 & 324.07 & 616.34 \\
\hline 9 May 2020 & 26.85 & 57.6 & 24.09 & 56.67 & 349.96 & 686.09 & 310.61 & 599.69 \\
\hline 10 May 2020 & 27.09 & 57.55 & 27.17 & 51.12 & 373.83 & 736.34 & 322.79 & 619.63 \\
\hline 11 May 2020 & 26.25 & 52.87 & 25.48 & 50.08 & 300.98 & 596.185 & 279.56 & 538.35 \\
\hline 12 May 2020 & 27.68 & 41.89 & 26.45 & 40.49 & 261.85 & 508.76 & 234.48 & 436.69 \\
\hline
\end{tabular}


Table 4. Cont.

\begin{tabular}{|c|c|c|c|c|c|c|c|c|}
\hline Date/Time & Ta_Glass_S & RH_Glass_S & Ta_Glass_N & RH_Glass_N & Sol_Glass_S & Par_Glass_S & Sol_Glass_N & Par_Glass_N \\
\hline 13 May 2020 & 29.08 & 45.79 & 28.27 & 43.59 & 234.97 & 461.19 & 212.01 & 410.27 \\
\hline 14 May 2020 & 28.81 & 49.86 & 28.45 & 48.36 & 276.09 & 536.35 & 265.42 & 492.15 \\
\hline 15 May 2020 & 28.62 & 53.85 & 28.21 & 50.68 & 317.51 & 620.54 & 272.07 & 451.68 \\
\hline 16 May 2020 & 21.29 & 89.2 & 21.07 & 82.14 & 99.4 & 189.56 & 84.42 & 112.38 \\
\hline 17 May 2020 & 20.92 & 76.66 & 20.89 & 72.15 & 108.5 & 203.24 & 102.44 & 166.55 \\
\hline DAY AVERAGE & 27.81 & 56.28 & 26.54 & 55.82 & 310.32 & 587.64 & 246.46 & 468.77 \\
\hline
\end{tabular}

Table 5. Mean night-time variations of climatic parameters over the measurement period.

\begin{tabular}{|c|c|c|c|c|c|c|c|c|}
\hline Date/Time & Ta_Glass_S & RH_Glass_S & Ta_Glass_N & RH_Glass_N & Sol_Glass_S & Par_Glass_S & Sol_Glass_N & Par_Glass_N \\
\hline 5 March 2020 & 16.95 & 75.26 & 15.51 & 83.51 & 0 & 0 & 0 & 0 \\
\hline 6 March 2020 & 17.03 & 100 & 17.01 & 98.36 & 0 & 0 & 0 & 0 \\
\hline 7 March 2020 & 17.13 & 97.33 & 17.06 & 94.78 & 0 & 0 & 0 & 0 \\
\hline 9 March 2020 & 16.44 & 91.75 & 16.73 & 89.95 & 0 & 0 & 0 & 0 \\
\hline 10 March 2020 & 17.02 & 99.42 & 17.16 & 99.18 & 0 & 0 & 0 & 0 \\
\hline 11 March 2020 & 17.08 & 96.63 & 17.25 & 97.3 & 0 & 0 & 0 & 0 \\
\hline 12 March 2020 & 16.56 & 85.46 & 16.81 & 91.09 & 0 & 0 & 0 & 0 \\
\hline 14 March 2020 & 15.21 & 79.14 & 15.44 & 86.13 & 0 & 0 & 0 & 0 \\
\hline 15 March 2020 & 16.02 & 76.48 & 16.16 & 81.19 & 0 & 0 & 0 & 0 \\
\hline 16 March 2020 & 15.99 & 78.5 & 16.13 & 82.09 & 0 & 0 & 0 & 0 \\
\hline 17 March 2020 & 15.89 & 84.44 & 15.97 & 93.01 & 0 & 0 & 0 & 0 \\
\hline 18 March 2020 & 16.48 & 99.51 & 16.76 & 88.49 & 0 & 0 & 0 & 0 \\
\hline 19 March 2020 & 17.07 & 99.95 & 17.19 & 93.27 & 0 & 0 & 0 & 0 \\
\hline 20 March 2020 & 17.03 & 100 & 17.18 & 96.44 & 0 & 0 & 0 & 0 \\
\hline 21 March 2020 & 17.12 & 100 & 17.05 & 99.89 & 0 & 0 & 0 & 0 \\
\hline 22 March 2020 & 16.98 & 99.99 & 16.93 & 99.99 & 0 & 0 & 0 & 0 \\
\hline 24 March 2020 & 17.19 & 100 & 17.29 & 96.35 & 0 & 0 & 0 & 0 \\
\hline 25 March 2020 & 17.28 & 100 & 17.36 & 100 & 0 & 0 & 0 & 0 \\
\hline 26 March 2020 & 17.21 & 100 & 17.19 & 100 & 0 & 0 & 0 & 0 \\
\hline 27 March 2020 & 16.92 & 100.2 & 17 & 100 & 0 & 0 & 0 & 0 \\
\hline
\end{tabular}


Table 5. Cont.

\begin{tabular}{|c|c|c|c|c|c|c|c|c|}
\hline Date/Time & Ta_Glass_S & RH_Glass_S & Ta_Glass_N & RH_Glass_N & Sol_Glass_S & Par_Glass_S & Sol_Glass_N & Par_Glass_N \\
\hline 28 March 2020 & 17.08 & 100 & 17.13 & 99.53 & 0 & 0 & 0 & 0 \\
\hline 29 March 2020 & 16.76 & 99.97 & 16.82 & 94.75 & 0 & 0 & 0 & 0 \\
\hline 30 March 2020 & 16.94 & 100 & 17.02 & 98.28 & 0 & 0 & 0 & 0 \\
\hline 1 April 2020 & 17.03 & 98.38 & 17.24 & 88.35 & 0 & 0 & 0 & 0 \\
\hline 2 April 2020 & 17.12 & 99.45 & 17.26 & 87.77 & 0 & 0 & 0 & 0 \\
\hline 3 April 2020 & 16.88 & 100 & 16.79 & 100 & 0 & 0 & 0 & 0 \\
\hline 4 April 2020 & 16.99 & 100 & 17.18 & 95.94 & 0 & 0 & 0 & 0 \\
\hline 6 April 2020 & 16.83 & 100 & 17.07 & 99.66 & 0 & 0 & 0 & 0 \\
\hline 7 April 2020 & 16.88 & 100 & 17.04 & 98.93 & 0 & 0 & 0 & 0 \\
\hline 8 April 2020 & 16.90 & 100 & 17 & 95.83 & 0 & 0 & 0 & 0 \\
\hline 9 April 2020 & 15.95 & 83.11 & 16.15 & 65.32 & 0 & 0 & 0 & 0 \\
\hline 10 April 2020 & 16.87 & 89.77 & 16.96 & 69.26 & 0 & 0 & 0 & 0 \\
\hline 11 April 2020 & 16.48 & 92.36 & 16.76 & 75.44 & 0 & 0 & 0 & 0 \\
\hline 12 April 2020 & 16.88 & 96.65 & 16.98 & 80.84 & 0 & 0 & 0 & 0 \\
\hline 13 April 2020 & 16.98 & 99.74 & 17.16 & 89 & 0 & 0 & 0 & 0 \\
\hline 14 April 2020 & 17.01 & 99.12 & 17.13 & 84.42 & 0 & 0 & 0 & 0 \\
\hline 17 April 2020 & 16.92 & 99.7 & 16.89 & 93.42 & 0 & 0 & 0 & 0 \\
\hline 18 April 2020 & 17.03 & 100 & 17.19 & 97.72 & 0 & 0 & 0 & 0 \\
\hline 19 April 2020 & 16.8 & 98.29 & 16.85 & 88.71 & 0 & 0 & 0 & 0 \\
\hline 20 April 2020 & 16.84 & 99.59 & 16.76 & 96.58 & 0 & 0 & 0 & 0 \\
\hline 21 April 2020 & 16.98 & 96.07 & 17.12 & 85.19 & 0 & 0 & 0 & 0 \\
\hline 22 April 2020 & 15.02 & 83.83 & 15.35 & 66.61 & 0 & 0 & 0 & 0 \\
\hline 23 April 2020 & 14.2 & 98.21 & 14.42 & 77.64 & 0 & 0 & 0 & 0 \\
\hline 24 April 2020 & 15.31 & 92.02 & 15.47 & 76.26 & 0 & 0 & 0 & 0 \\
\hline 25 April 2020 & 16.96 & 100 & 17.19 & 96.48 & 0 & 0 & 0 & 0 \\
\hline 26 April 2020 & 14.98 & 99.88 & 15.38 & 81.05 & 0 & 0 & 0 & 0 \\
\hline 27 April 2020 & 16.88 & 100 & 17.08 & 100 & 0 & 0 & 0 & 0 \\
\hline 28 April 2020 & 15.81 & 96.11 & 15.8 & 77.79 & 0 & 0 & 0 & 0 \\
\hline 29 April 2020 & 16.02 & 72.88 & 16.2 & 68.22 & 0 & 0 & 0 & 0 \\
\hline 30 April 2020 & 18.32 & 72.02 & 18.32 & 67.28 & 0 & 0 & 0 & 0 \\
\hline
\end{tabular}


Table 5. Cont.

\begin{tabular}{|c|c|c|c|c|c|c|c|c|}
\hline Date/Time & Ta_Glass_S & RH_Glass_S & Ta_Glass_N & RH_Glass_N & Sol_Glass_S & Par_Glass_S & Sol_Glass_N & Par_Glass_N \\
\hline 1 May 2020 & 17.46 & 100 & 17.66 & 96.65 & 0 & 0 & 0 & 0 \\
\hline 2 May 2020 & 17.41 & 99.98 & 17.52 & 98.22 & 0 & 0 & 0 & 0 \\
\hline 3 May 2020 & 17.42 & 99.78 & 17.66 & 93.63 & 0 & 0 & 0 & 0 \\
\hline 5 May 2020 & 17.08 & 99.08 & 17.44 & 91.03 & 0 & 0 & 0 & 0 \\
\hline 6 May 2020 & 17.11 & 99.25 & 17.39 & 88.58 & 0 & 0 & 0 & 0 \\
\hline 7 May 2020 & 17.47 & 75 & 17.72 & 69.01 & 0 & 0 & 0 & 0 \\
\hline 8 May 2020 & 17.11 & 98.23 & 17.08 & 94.88 & 0 & 0 & 0 & 0 \\
\hline 10 May 2020 & 16.83 & 97.22 & 16.72 & 81.08 & 0 & 0 & 0 & 0 \\
\hline 11 May 2020 & 17.14 & 92.09 & 17.21 & 75.56 & 0 & 0 & 0 & 0 \\
\hline 12 May 2020 & 17.92 & 77.59 & 18.17 & 70.59 & 0 & 0 & 0 & 0 \\
\hline 13 May 2020 & 24.06 & 35.54 & 24.32 & 30.56 & 0 & 0 & 0 & 0 \\
\hline 14 May 2020 & 18.18 & 98.27 & 18.63 & 91.24 & 0 & 0 & 0 & 0 \\
\hline 15 May 2020 & 17.94 & 81.58 & 18.08 & 73.63 & 0 & 0 & 0 & 0 \\
\hline 16 May 2020 & 17.92 & 99.78 & 18.17 & 95.15 & 0 & 0 & 0 & 0 \\
\hline 17 May 2020 & 17.06 & 100 & 17.12 & 99.95 & 0 & 0 & 0 & 0 \\
\hline NIGHT AVERAGE & 16.93 & 93.91 & 17.05 & 88.14 & 0 & 0 & 0 & 0 \\
\hline
\end{tabular}




\section{Conclusions}

IoT devices can collect vast amounts of environmental, soil, and crop performance data, thus building time series data that can be analyzed to forecast and compute recommendations and deliver critical information to farmers in real time. In this sense, the added-value from the farmers' perspective is that such smart farming techniques have the potential to deliver a more sustainable agricultural production, based on a more precise and resource-efficient approach in the complex and versatile agricultural environment [17].

An integrated IoT-based robotic greenhouse control system, a cablebot device, was developed together with a prototype electric valve (coordinator) and the necessary interface app. The operation of the whole system has been initially tested and is now being installed in a greenhouse installation, belonging to the Agriculture Department of the University of Patras. The system can collect a series of crop sensitive data and performs autonomously several tasks such as automated smart irrigation.

\section{Future Work}

On-site testing with real measurements, data collection, and mapping will be the subject of further study. Taking into account actual data, we will conduct testing of some internal equations. Collecting real data could lead to new ideas and an extension of our system. Realistic future improvement proposals could be: our system to be fully functional in open area environments for low temperatures; a possible movement of the cablebot, as we know that the behavior of the drive yarn varies with temperature; Gaia in case of ice could walk; Could a possible move in the future with tracks provide a solution; The degrees of movement of the robot need improvement for perimeter movement in space; Application of extra technologies for greater energy autonomy. Development of 3DS system for open fields.

Author Contributions: Conceptualization, D.B. \& K.-N.P.; Formal analysis, V.T.; Investigation, D.B. and K.-N.P.; Methodology, V.T. and D.T.; Project administration, A.K.; Supervision, D.T.; Writingoriginal draft, V.T.; Writing-review \& editing, D.T. and A.K. All authors have read and agreed to the published version of the manuscript.

Funding: The paper was funded in the frame of "Development of Intelligent and Energy-autonomous Greenhouse Using Innovative Technologies to Improve Productivity and Product quality" (IEnGreen) program, MIS:5045455 Smart Specialization Strategy-RIS3.

Informed Consent Statement: Not applicable.

Conflicts of Interest: The authors declare no conflict of interest.

\section{References}

1. Dwivedi, A.; Naresh, R.K.; Kumar, R.; Yadar, R.S.; Kumar, R. PRECISION AGRICULTURE. 2017.

2. Gonzalez, F.; McFadyen, A.; Puig, E. New Technologies in Precision Agriculture. Advances in Unmanned Aerial Systems and Payload Technologies for Precision Agriculture; Routledge: London, UK; Taylor \& Francis Group: London, UK, 2019.

3. Vasudevan, A.; Kumar, D.A.; Bhuvaneswari, N.S. Precision farming using unmanned aerial and ground vehicles. In Proceedings of the 2016 IEEE Technological Innovations in ICT for Agriculture and Rural Development (TIAR), Chennai, India, 15-16 July 2016; pp. 146-150.

4. $\quad$ El-Naggar, A.G.; Hedley, C.B.; Horne, D.; Roudier, P.; Clothier, B.E. Soil Sensing Technology improves application of irrigation water. Agric. Water Manag. 2019, 228. [CrossRef]

5. Smith, R.J.; Baillie, J.N.; McCarthy, A.C.; Raine, S.R.; Baillie, C.P. Review of Precision Irrigation Technologies and Their Application. National Centre for Engineering in Agriculture Publication; USQ: Toowoomba, Australia, 2010; p. 1003017/1, ISBN 1921025298.

6. Jackson, R.D.; Idso, S.B.; Reginato, R.J.; Pinter, P.J., Jr. Canopy Temperature as a Crop Water Stress Indicator. Water Resour. Res. 1981, 17, 1133-1138. Available online: https:/ / ui.adsabs.harvard.edu/link_gateway/1981WRR (accessed on 10 December 2020). [CrossRef]

7. Akkaş, M.A.; Sokullu, R.An IoT-based greenhouse monitoring system with Micaz motes. Procedia Comput. Sci. 2017, 113, 603-608. [CrossRef]

8. Bitas, D.; Papastavros, K.N.; Tsipianitis, D. A Smart Cablebot for Spectral Imaging and Micro-climate measurements inside Greenhouses. In Proceedings of the 11th International Conference on Information, Intelligence, Systems and Applications, Piraeus, Bangkok, Thailand, 1-3 July 2020. 
9. Kavga, A.; Bitas, D.; Papastavros, K.N.; Prapopoulos, M.; Kotsiris, G. Development of an integrated IoT-based greenhouse control cablebot system. In Proceedings of the Information and Communication Technologies in Agriculture, Food and Environment (HAICTA 2020), Thessaloniki, Greece, 24-27 September 2020.

10. Comba, L.; Gay, P.; Piccarolo, P.; RicaudaAimonino, D. Robotics and Automation for Crop Management: Trends and Perspective. In Proceedings of the International Conference Ragusa (SHWA), Ragusa Ibla Campus, Italy, 16-18 September 2010.

11. Donovan, K. Anytime, anywhere: Mobile Devices and Services and Their Impact on Agriculture and Rural Development. In ICT, in Agriculture (Updated Edition). Connecting Smallholders to Knowledge, Networks and Institutions; 2017; pp. 49-70. [CrossRef]

12. Rojo, F.; Kizer, E.; Upadhyaya, S.; Ozmen, S.; Ko-Madden, C.; Zhang, Q. A leaf monitoring system for continuous measurement of plant water status to assist in precision irrigation in grape and almond crops. Int. Federation Autom. Control 2016, 49, 209-215. [CrossRef]

13. Dhillon, R.S.; Upadhyaya, S.K.; Rojo, F.; Roach, J.; Coates, R.W.; Delwiche, M.J. Development of a continuous leaf monitoring system to predict plant water status. Trans. ASABE 2017, 60, 1445-1455. [CrossRef]

14. Yu, H.; Liu, D.; Chen, G.; Wan, B.; Wang, S.; Yang, B. InScience Direct. A neural network ensemble method for precision fertilization modeling. Math. Comput. Model. 2010, 51, 1375-1382. [CrossRef]

15. Sollazzo, A.; Colliaux, D.; Garivani, S.; Minchin, J.; Garlanda, L.; Hanappe, P. Automated vegetable growth analysis from outdoor images acquired with a cablebot.

16. Mahajan, U.; Bundel, B.R. Drones for Normalized Difference Vegetation Index (NDVI), to Estimate Crop Health for Precision Agriculture: A Cheaper Alternative for Spatial Satellite Sensors. In Proceedings of the International Conference on Innovative Research in Agriculture, Food Science, Forestry, Horticulture, Aquaculture, Animal Sciences, Biodiversity, Ecological Sciences and Climate Change (AFHABEC-2016), Siliguri, India, 17-18 March 2016.

17. Adamides, G.; Kalatzis, N.; Stylianou, A.; Marianos, N.; Chatzipapadopoulos, F.; Giannakopoulou, M.; Papadavid, G.; Vassiliou, V.; Neocleous, D. Smart Farming Techniques for Climate Change Adaptation in Cyprus. Atmosphere 2020, 11, 557. [CrossRef] 